Originally published as:

Klotz, C., Aebischer, T., Seeber, F.

Stem cell-derived cell cultures and organoids for protozoan parasite propagation and studying host-parasite interaction

(2012) International Journal of Medical Microbiology, 302 (4-5), pp. 203-209.

DOI: 10.1016/j.jimm.2012.07.010

AUTHOR MANUSCRIPT. (C) Elsevier (2012): This is the author's version of the work. It is posted here by permission of Elsevier for personal use, not for redistribution. Some changes resulting from the publishing process, such as editing, corrections, structural formatting, and other quality control mechanisms may not be reflected in this document. Some changes may have been made to this work since being accepted for publication. A definitive version was subsequently published in International Journal of Medical Microbiology, 302, 4-5, 203-209. 10.1016/j.ijmm.2012.07.010 


\title{
Stem cell-derived cell cultures and organoids for protozoan parasite propagation and studying host-parasite interaction
}

\author{
Christian Klotz, Toni Aebischer and Frank Seeber
}

FG 16 Parasitologie, Robert Koch Institut, 13353 Berlin, Germany

Address for correspondence: Frank Seeber, FG 16, Robert Koch Institut, Nordufer 20, 13353

Berlin, Germany. Tel: +49-30-18754-2856. Fax: +49-30-18754-2615. E-mail: see-

berf@rki.de

\section{Summary}

Possibilities to study the biology of human protozoan parasites and their interaction with the host remain severely limited, either because of non-existent or inappropriate animal models or because parasites cannot even be cultured in vitro due to strict human-host specificity or physiology. Here we discuss the prospects of using induced pluripotent stem cell (iPSC)derived culture systems including organoids as a strategy to address many of these experimental bottlenecks. iPSCs already allow the generation of differentiated cell cultures for many human organs, and these cells and derivatives are amenable to reverse genetics in combination with advanced tools for genetic manipulation. We present examples of blood, neuron, liver, and intestine-dwelling protozoa, i.e. Plasmodium falciparum, Toxoplasma gondii and Giardia duodenalis, where iPSCs or organoids would allow addressing questions of cell and developmental biology, immunology, and pharmacology in unprecedented ways. Starting points and resources for iPSC experimentation are briefly discussed.

\section{Keywords}

Induced pluripotent stem cells; organoids; intestinal infection; Giardia duodenalis; Toxoplasma gondii; Plasmodium falciparum 


\section{Introduction}

The ability to propagate pathogens in vitro in order to study their biology and interaction with their host is a prerequisite for understanding infectious diseases, and this is as important today as it was for Robert Koch when he first identified and cultivated Bacillus anthracis as the etiological agent causing anthrax (Koch, 1876). The study of protozoan parasites is no exception to this. Although a substantial body of literature exists describing in vitro methods for their propagation (e.g. Taylor and Baker, 1987; Visvesvara and Garcia, 2002) a large number of problems and restrictions remain.

Some parasites cannot be cultivated in vitro at all, e.g. Cyclospora cayetanensis (Ortega and Sanchez, 2010); for others such as Cryptosporidium sp. (Arrowood, 2002) or Giardia duodenalis (Benere et al., 2010), existing in vitro or in vivo systems are unsatisfactory, and axenic culture systems that would allow one to dissect biochemical dependencies for growth are not available for most medically important parasites, including all Apicomplexa. Host specificity is another important obstacle against the propagation of protozoan, in particular intracellular parasites, such as Plasmodium sp. or Eimeria sp., or for studying host species-restricted life cycle segments such as sexual reproduction of the apicomplexan parasites Toxoplasma gondii and Neospora caninum, which only occur in feline or canine hosts, respectively. The recent progress in stem cell biology, i.e. the in vitro generation of pluripotent stem cells and organoids from those, holds great promise as a solution for a number of the aforementioned problems in the study of specific, mainly human host-parasite combinations. In this review we aim to highlight some of the opportunities and remaining challenges of these developments for the study of protozoan parasites by focusing on select examples.

\section{What are stem cells, and how can they be generated in vitro?}

In 1998 the propagation of pluripotent cells from human blastocysts, cultured on mouse embryonic fibroblasts in serumcontaining media, was reported (Thomson et al., 1998). Thus, a protocol became available for the derivation of human - in this case embryonic - stem cells, i.e. cells with the capacity for long-term selfrenewal and the potential to differentiate into the components and derivatives of all three embryonic germ layers. While this was a technical breakthrough, it immediately provoked a necessary ethical discussion (Miller and Bloom, 1998) and subsequently led to legislation in different countries to regulate when and how the technique or working with human embryonic stem cells (hESCs) would be acceptable (e.g. in Germany see http://www.rki.de/DE/ Content/ Kommissionen /ZES/zes_node.html). Eight years later Takahashi and Yamanaka published a protocol that allowed for the reprogramming of differentiated murine fibroblasts by expression of just four transcription factors, Oct-4, Sox-2, Krüppel-like factor 4 (Klf-4), and c-myc (Takahashi and Yamanaka, 2006). Thereby they were able to re-establish the intracellular signaling circuitry that induces pluripotent stem cells (iPSCs). Since then several solutions for delivering such reprogramming factors into mouse and human somatic cells have been developed even to the level of commercial products, and these include alternatives such as using small molecules and miRNAs (for review see Hanna et al., 2010; Robinton and Daley, 2012; see also Supplementary Table 1 for selected iPSCrelated resources). The iPSC technology not only poses less severe ethical issues, it also offers a real possibility to study the basis of genetic diseases, because iPSC lines can be established from affected patients (Sadelain et al., 2011). Additionally, protocols to re-derive differentiated cells of different types from iPSC are rapidly being developed. Needless to say, these 
advances together with initiatives to establish iPSC banks (Rao et al., 2012) open opportunities to study host species- and host genotype-specific parasite interactions. Moreover, the possibility to genetically engineer human iPSCs with a high efficiency (Hockemeyer et al., 2011) in order to introduce at a defined site a transgene or disrupt the endogenous gene(s), thus creating functional mutants, will add even more impetus to this (see next section). In the context of protozoan parasitic infections, unlimited access to cells of the hematopoietic lineages, to neuronal cells, to liver and gastrointestinal cell types, or to organoids mimicking the respective organs is the promise that iPSCs of relevant host species hold (see below and Table 1). Methods for efficient transdifferentiation of readily available cells such as fibroblasts to more difficult-to-get cells complement the choices (Vierbuchen and Wernig, 2011).

\section{Generation of human hematopoietic cells with designed genetic makeup - a novel resource for studying Plasmodium- erythrocyte interactions}

iPSCs are an attractive platform for the propagation of human Plasmodium species due to the strict host cell specificity of the latter for human erythrocytes or hepatocytes (Schuster, 2002). Recent advances in the field of large-scale in vitro production of functional red blood cells (RBCs) from iPSCs (for review see Dravid and Crooks, 2011; Timmins and Nielsen, 2011) provide exciting opportunities for studying the respective host-parasite interactions. Through evolution, the burden of human malaria has resulted in the selection of a number of gene mutations in the human population that affect RBC function. These mutations lower morbidity and mortality due to malaria in the affected human beings (Bauduer, 2012; Gouagna et al., 2010) and have provided important clues to the intraerythrocytic biology of $P$. falciparum. It can be assumed that more host erythrocyte proteins are important in this context, as suggested by recent studies (Bei et al., 2010; Crosnier et al., 2011). Based on protocols described previously (Giarratana et al., 2005), these investigators used CD $34^{+}$ precursor stem cells purified from human bone marrow and knocked down glycophorin A and basigin, respectively, by RNAi before differentiating these cells to $\mathrm{RBC}$ and infecting them with $P$. falciparum. However, the potential of designing specific gene deletions, site-directed specific mutations and modifications or corrections with the aid of so-called zinc finger nucleases (ZFNs; Collin and Lako, 2011) or transcription activator-like effector nucleases (TALENs; Mussolino and Cathomen, 2012) in iPSCs (Hockemeyer et al., 2009; Hockemeyer et al., 2011) allows one to refine and extend the design of such experiments (see Fig. 1). The subsequent differentiation of such mutated cells into erythrocytes would greatly expand the repertoire of mutant erythrocytes amenable to functional testing. Moreover, access to human $\mathrm{CD} 34^{+}$precursor stem cells or already known mutant erythrocytes from patients is limited, and iPSC-derived erythrocytes from such individuals would facilitate research on such $P$. falciparuminfected cells.

A further application of this technology is to humanize mice with such cells (Arnold et al., 2011; Legrand et al., 2009) in order to study many aspects of host-parasite relation in vivo in an unprecedented way. The generation of mice with gene defects that prevent formation of $\mathrm{T}$ and $\mathrm{B}$ cells (scid or rag mutations) and natural killer cells (through IL-2 receptor $\gamma$ chain deficiency) resulted in models that sustain meaningful numbers of human blood cells (Ito et al., 2002; Traggiai et al., 2004), and these models are continuously being improved (Brehm et al., 2012; Strowig and Flavell, 2012). The individual techniques have all been described (see Fig. 1 and Table 1), and it is only a matter of time until the first studies implementing it for $P$. falciparum are published. 


\section{Human neuronal cell lines and Toxoplasma gondii}

One reason that $T$. gondii has emerged as a prominent model organisms for protozoan parasites is due to its ease of cultivation and its very broad host species and host cell range, including mutant cell lines that have been important to the study of many aspects of host-parasite interaction (Pfefferkorn, 1990). It could be argued that stem cell-derived systems offer little extra when studying $T$. gondii host-parasite interplay. However, the latent, chronic stage of $T$. gondii, the so-called bradyzoites, are found predominantly in brain, heart, and muscle tissue. These tissues are readily available, e.g. from experimentally infected mice, but equivalent human cells are difficult to obtain. iPSC-derived neuronal, cardiac, or muscle cells could, however, deliver sufficient quantities of well-defined samples that would enable comparative analyses relevant to human disease. For example, the recently reported direct reprogramming (transdifferentiation) of human fibroblasts into neurons (Ambasudhan et al., 2011; Pang et al., 2011; Pfisterer et al., 2011) opens exciting possibilities to study this particular host cell -parasite interaction in more detail. It would allow the evaluation of results obtained with infected rodent neurons that suggested an influence of $T$. gondii on neuronal dopamine metabolism (Prandovszky et al., 2011).

\section{Human stem cell-derived liver cells for Plasmodium research on sporozoite in- vasion and development of exoerythro- cytic forms (EEF)}

The clinically silent malaria liver stage has become a major research area, because it represents one of the bottlenecks in the Plasmodium life cycle and is probably the most promising stage for vaccine development (Mueller et al., 2005; Nussenzweig et al., 1967). To date, the liver stage can only be studied in depth in animal models of malaria (there is no option for the human-specific Plasmodium species) and hepatocyte cell lines. Adult, untransformed human liver cells are not routinely used due to the fact that they do not proliferate in vitro and are difficult to cryopreserve (Terry and Hughes, 2009). Still very little is known as to why mammalian Plasmodium sporozoites specifically target hepatocytes as their primary host cells for subsequent EEF development (Hafalla et al., 2011; Silvie et al., 2008). Recent advances in differentiating human ESCs or iPSCs into hepatocyte-like cells (Chen et al., 2012; Schwartz et al., 2005; Song et al., 2009; Touboul et al., 2010) or to transdifferentiate human fibroblasts into cells with hepatocyte-like properties (Sekiya and Suzuki, 2011) may for the first time offer opportunities to study aspects of this host cell specificity of human-specific liver stages of $P$. falciparum or $P$. vivax in more depth. Additionally, we lack knowledge about the full repertoire of antigens that are presented during the arrested EEF development. Genetically attenuated parasites showing this arrest can confer protection in murine models (Mueller et al., 2005). Stem cell-derived human hepatocytes could help identify or test presented (protective) antigens from respective mutants of human Plasmodium species in order to develop subunit vaccines against sporozoites and liver stages, as this is of high priority in combating malaria (Kappe et al., 2010).

Non-parenchymatic liver cells (NPLCs), i.e. stellate cells, liver sinusoidal endothelial cells (LSECs) and Kupffer cells, are highly specific cells with unique properties that contribute significantly to the liver tissue and are vitally important for liver function during homeostasis and infection (Protzer et al. 2012). While little is known about the role of NPLCs during the hepatic phase of human malaria, mouse data revealed that during the transmigration event, sporozoites are in intimate contact with LSECs and pass through Kupffer cells in order to enter the liver (Frevert et al., 2008; Klotz and Frevert, 2008). Obviously, the development of a method to derive NPLCs from stem cells would enable stud- 
ies on the role of these cells (e.g. for antigen presentation during the hepatic stage of Plasmodium) to be intensified, but such a protocol is currently not available. Studies of $E$. histolytica-LSEC interactions (Faust et al., 2011) in order to better understand the process behind amoebiasisinduced liver abscesses could also benefit from stem cell-derived NPLCs.

\section{Intestinal organoids as a new tool for enteric protozoa and for studying habi- tat-parasite interactions}

Intestinal protozoan parasites are phylogenetically quite divergent but share the gut as a common habitat or entry point into the host. These organisms possess diverse biology for survival and replication in different niches; for example G. duodenalis or Entamoeba spp. dwell in the intestinal lumen, and Cryptosporidium spp. or $T$. gondii live within intestinal cells (Stark et al., 2009). Research on many of these organisms is hampered by a lack of appropriate in vitro culture systems. Stem cellderived systems can offer new avenues to investigate the organ-specific interactions of these parasites.

In seminal papers published in 2009 , two independent research groups reported different methods for the establishment of stem cell-based organoids from primary mouse intestinal tissue (Ootani et al., 2009; Sato et al., 2009). Ootani and colleagues established a more complex culture system from minced whole intestinal tissue embedded in a three-dimensional collagen structure with support of stromal cells (Ootani et al., 2009). Sato et al. succeeded in establishing organoid cultures from isolated crypts and from single Lgr5 markerpositive cells using a matrigel matrix and serum-free medium supplemented with Wnt antagonist R-Spondin1, TGF-beta signaling inhibitor Noggin and epidermal growth factor (Sato et al., 2009; Sato et al., 2011b). The latter system is particularly attractive, as no stromal cell support is necessary and it can be implemented relatively easily in most laboratories. We established such organoids following the protocol of Sato et al. from primary mouse crypts isolated from various mouse strains (Fig. 2). The observed crypt-villus structures consist of all epithelial, stem cellderived progenitor cells, i.e. enterocytes, paneth cells, goblet cells and enteroendocrine cells, but lack cells of mesenchymal or hematopoietic lineages (Sato et al., 2009). Organoids simulate the in vivo situation much better than for instance the intestinal cell lines currently used for studying host-parasite interactions in vitro. Additionally, they are amenable to live cell imaging techniques akin to intravital microscopy (Chieppa et al., 2006). Moreover, since organoids can be generated from different tissues of the gut, including the small intestine and colon (Sato et al., 2009; Sato et al., 2011a, b; Yui et al., 2012), site-specific interaction with a particular pathogen can be studied.

Recently, human intestinal organoids have been successfully established on the one hand from hESCs and hiPSCs (McCracken et al., 2011; Spence et al., 2011), and on the other hand starting from primary human tissue out of healthy and diseased patients (Sato et al., 2011a). Therefore in the future, we might be able to establish new in vitro culture systems for the sparsely studied human intestinal protozoan parasites that are still inadequately cultured or not culturable (see Table 1).

\section{Giardia duodenalis}

While in vitro studies on G. duodenalis are relatively easy to perform, it is much more difficult to investigate the events in the host gut that lead to disease and pathology, particularly in humans. Currently, researchers resort to animal models or studies of parasites with immortalized intestinal cell lines, both of which have their obvious and distinct limitations. The impact of the various proposed disease mechanisms on parasite pathogenicity (reviewed in Ankarklev et al., 2010; Cotton et al., 
2011), such as induction of apoptosis and loss of intestinal barrier function, and the role of putative parasite virulence factors in these processes is currently unknown. Intestinal organoid cultures derived from iPSCs or from human intestinal tissue would greatly advance our means to study G. duodenalis pathogenicity and could help define virulence factors relevant for human infection. Currently, intestinal organoids lack cells of the immune system but offer the possibility to study the direct interaction of the parasites with welldifferentiated intestinal epithelial tissue as well as early events during infection. Furthermore, it seems possible to elucidate host factors affecting $G$. duodenalis infection outcome by using organoids derived either from patients with particular disease manifestations (e.g. from volunteers with symptomatic vs. asymptomatic infections) or from genetically modified iPSCs.

Another attractive application for intestinal organoids is to use them to improve the success rate of parasite adaptation to in vitro culture from clinical material. Although cell-free culture systems with trophozoites derived from biopsies or generated from cysts via in vitro excystation have been pioneered (Bingham and Meyer, 1979; Meyer, 1970), it is still not possible to derive cultures from all distinct $G$. duodenalis genotypes. This resulted in a large research bias towards easily culturable isolates (Smith et al., 1982). An organoid infection system enabling the cultivation of so far non-culturable isolates would represent a breakthrough and, for example, establish the basis for functional epidemiology of giardiasis.

\section{Toxoplasma gondii}

T. gondii's usual port of entry into its hosts is through the intestinal route via ingestion of tissue cysts or oocysts. While this initial infection process is documented to some degree in mice (Barragan and Hitziger, 2008; Barragan and Sibley, 2002) intestinal organoids could provide a relevant model for studying this aspect in the hu- man system.

An exciting prospect of the use of intestinal organoids is the possibility to approach the in vitro reconstruction of the sexual reproductive cycle of $T$. gondii. The latter plays a central role in the creation of genotypes of different virulence, but at a scale that has previously not been anticipated (Rao et al., 2012; Wendte et al., 2011). Sexual differentiation only takes place in cats and other felids. Thus, the challenge is to establish feline intestinal organoids and find in vitro conditions that would allow the sexual cycle to commence (and finish). It would provide an opportunity to analyze this poorly understood process under defined conditions and follow the process in real time through live cell imaging. Furthermore, such a culture system may offer an initial platform for vaccine or drug testing aimed at blocking oocyst formation and thereby dissemination.

\section{iPSCs as screening and evaluation plat- forms for new drugs}

Although most of the excitement over using iPSCs for drug screening purposes is currently in the field of monogenic human diseases (Ebert and Svendsen, 2010; Grskovic et al., 2011), screening programs intended to identify novel anti-protozoan parasite drugs would also benefit from the availability of differentiated cells usually not easily accessible, for example neurons. Stem cell-derived, differentiated cells are thought to allow more sensitive preclinical toxicology testing (i.e. for cardiotoxicity, hepatotoxicity, genotoxicity, and reproductive toxicology) of drug candidates than conventional cell systems do (Davila et al., 2004). Also, exploring the basis of differential drug pharmacology, kinetics, and metabolism in different individuals (frequently reflected as apparent "resistance" against drug X) using iPSCs derived from such patients for a given parasitic disease could greatly help in tailoring treatment regimens with approved, cheap, and safe drugs, thereby possibly extending the half-life of some anti- 
infectives in the clinics as in the case of malaria (Kerb et al., 2009; Paganotti et al., 2011).

\section{Conclusions}

Research exploiting iPSCs and their derived cells is still a very young field. Obviously, iPSC-derived cells and organ-like models have a number of caveats and disadvantages. Establishing protocols for one's own special purposes is not trivial. The requirement for expensive growth and differentiation factors currently make this approach very costly. Organ-like models still do not reproduce the situation in vivo; e.g. organoids often lack particular cell types such as immune cells or other components of the mimicked organ (e.g. the flora in gastrointestinal organoids), and this might be problematic. However, many step-by-step protocols and commercially available reagents (including established human iPSCs) already exist, and methods improve at a remarkable speed. Prices for reagents depend on demand and can drop quickly. For particular research questions, lack of complexity (e.g. additional cell types) may also be advantageous, offering a basic cellular model where complexity levels can be added as desired. Thus, we believe that the promises iPSC-based approaches offer to the study of protozoan parasites and host-specific interactions are realistic, and the opportunities should be seized.

\section{Acknowledgements}

We thank Kazimierz Madela from the RKI imaging facility for help with the confocal imaging and Marc-Jan Gubbels for comments. 
Table 1: Potential applications of stem cell-derived primary tissues/cells for research on the host-pathogen interaction of protozoan parasites

\begin{tabular}{cccc}
$\begin{array}{c}\text { Differentiated } \\
\text { cells/tissue * }\end{array}$ & $\begin{array}{c}\text { (Stem) Cell source and } \\
\text { technical references * }\end{array}$ & $\begin{array}{c}\text { Protozoan } \\
\text { pathogen }\end{array}$ & $\begin{array}{c}\text { Examples of possible } \\
\text { application }\end{array}$ \\
\hline
\end{tabular}

\section{Hemopoietic cells}

$\begin{array}{llll}\text { Erythrocytes } & \text { hiPSCs } & \begin{array}{l}\text { P.falciparum and } \\ \text { (D.vivax (blood stage) }\end{array} & \begin{array}{l}\text { Mutant erythrocytes for } \\ \text { studying metabolite } \\ \text { transport }\end{array} \\ & \text { Timmins and Nielsen, 2011) } & \text { Babesia spp. } & \end{array}$

\section{Neuronal tissue}

Neurons

Fibroblasts (transdifferentiation)

T. gondii

(Ambasudhan et al., 2011; Pang

et al., 2011; Pfisterer et al.,

2011)

hESCs, hiPSCs

(Lie et al., 2012)

\section{Liver}

Hepatocytes

hiPSCs, hESCs

(Cai et al., 2007; Chen et al.,

2012; Duan et al., 2007;

Schwartz et al., 2005; Song et

al., 2009; Touboul et al., 2010)

Fibroblasts (transdifferentiation)

(Sekiya and Suzuki, 2011)

$$
\begin{aligned}
& \text { P. falciparum and } \\
& \text { P. vivax }
\end{aligned}
$$

Studying nutrient acquisition, replication, and antigen presentation in primary human (mutant) hepatocytes

Revealing underlying pathogenicity factors of human liver/hepatocyte destruction
Hollow fiber / organoids
miPSCs and mESCs

(Amimoto et al., 2011;

Mizumoto et al., 2008)

\section{Intestine}

Intestinal organoids
hiPSCs, human intestinal crypts

(McCracken et al., 2011; Sato et al., 2011a; Spence et al., 2011)

Mouse $\operatorname{Lrg} 5^{+}$cells, mouse intestinal crypts

(Ootani et al., 2009; Sato et al., 2011a, b, 2009)
G. duodenalis

Entamoeba spp. Balantidium spp.

Cryptosporidium spp.

Cyclospora spp.
Improved in vitro culture of specific genotypes, studying virulence/ pathogenicity factors

Studying pathogenicity of intestinal amoebiasis and balantidiosis

Improved in vitro culture, drug and disinfectant screening, studying 
biology of life cycle

stages, viability assays

T. gondii

Recapitulating host-

parasite interactions at the

primary infection site

* The different stem cell sources and differentiated cells can be combined with different protozoa, depending on the intended experiment. 


\section{Legends to illustrations}

\section{Figure 1}

Driven by specific mixes of growth and differentiation factors, a variety of defined, differentiated cell types and even organoids can be derived from iPSCs (for generic iPSC protocols see Rajarajan et al., 2012). Direct re-programming, i.e. transdifferentiation of fibroblasts etc., to neurons by respective growth and differentiation factors is also possible. Engineered proteins containing zinc fingers or transcription activator-like effector domains fused to nucleases, called ZFN and TALEN, respectively, are used to create double-strand DNA breaks at predetermined sites in the genome (for technical resources see Sanjana et al., 2012). The breaks in turn are repaired by end joining and, in the presence of DNA constructs homologous to the chosen region, by homologous recombination-mediated repair. Thereby site-specific mutations/insertions can be introduced at the level of starting cells (e.g. fibroblasts) or iPSCs. Infection of iPSCs, of iPSCderived cell types of organoids, or even of mice humanized by the engraftment of hematopoietic precursor cells etc., with the parasite of choice offer different avenues for pathogen propagation and host interaction studies.

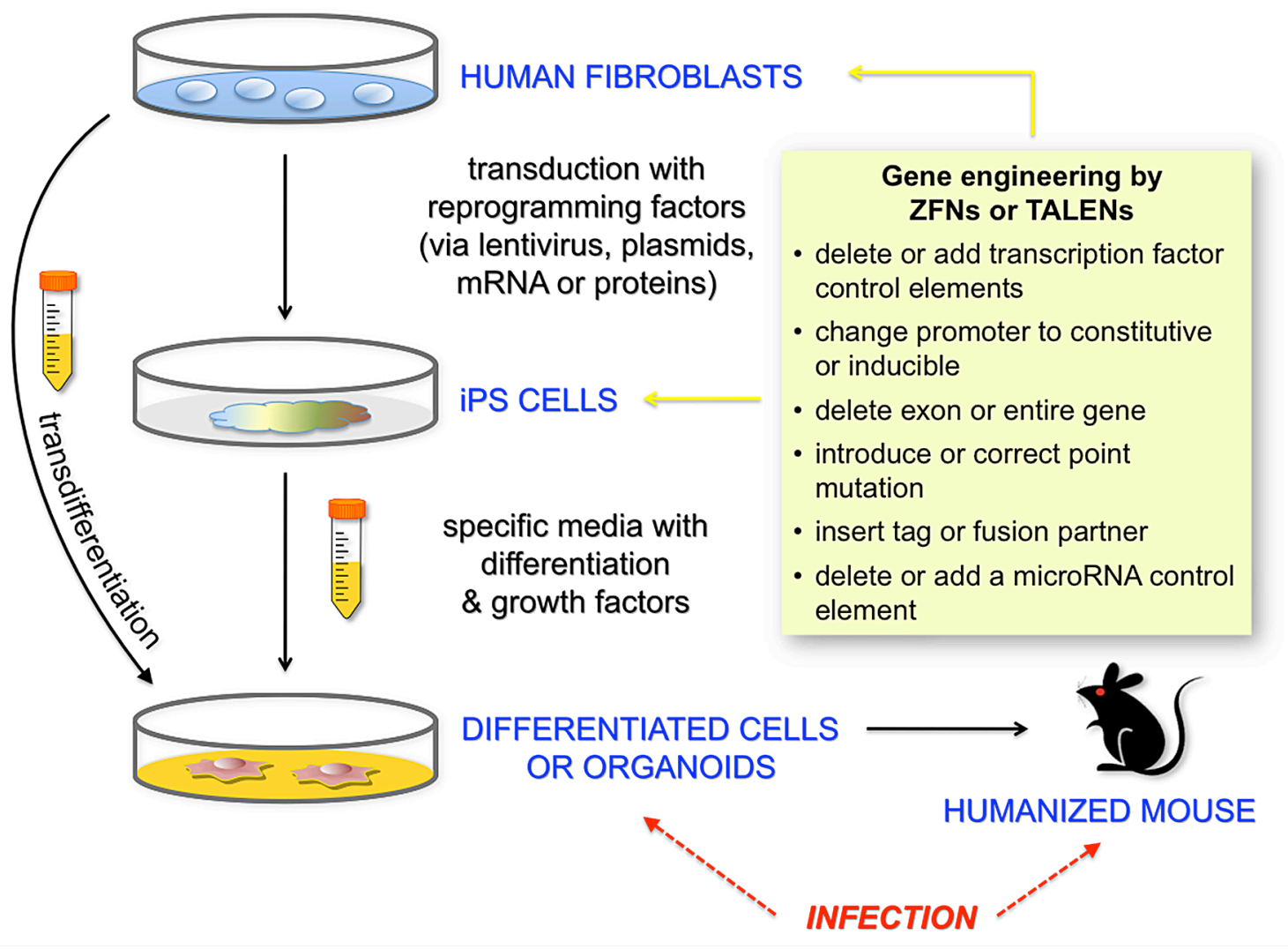




\section{Figure 2}

Intestinal organoid cultures to study host-parasite interaction. A, B: Long-term cultures of cryptderived intestinal organoids. Note the enclosed crypt-villous-like structures with luminal shedding of jaded enterocytes. C1-C4: Confocal imaging of proliferating cells of organoid cultures visualized by 5-ethynyl-2'-deoxyuridine (Edu)-incorporation. C1, Dapi (blue,); C2, Edu (red); C3, Nomarski interference; C4, merge of C2 and C3. Scale bar $=20 \mu \mathrm{m}$. D1: Immunofluorescence image of an intestinal organoid infected with tachyzoites of the RH strain of T. gondii $48 \mathrm{~h}$ post infection. Dapi (blue); tachyzoite surface was stained with anti-SAG1 mab DG52 (green). The fluorescence image was merged with a Nomarski interference image. D2: Enlargement of the fluorescent image from D1 (white square). Note the rosette-like structures of intracellular parasites in the epithelial layer, typical of RH strain tachyzoite replication.

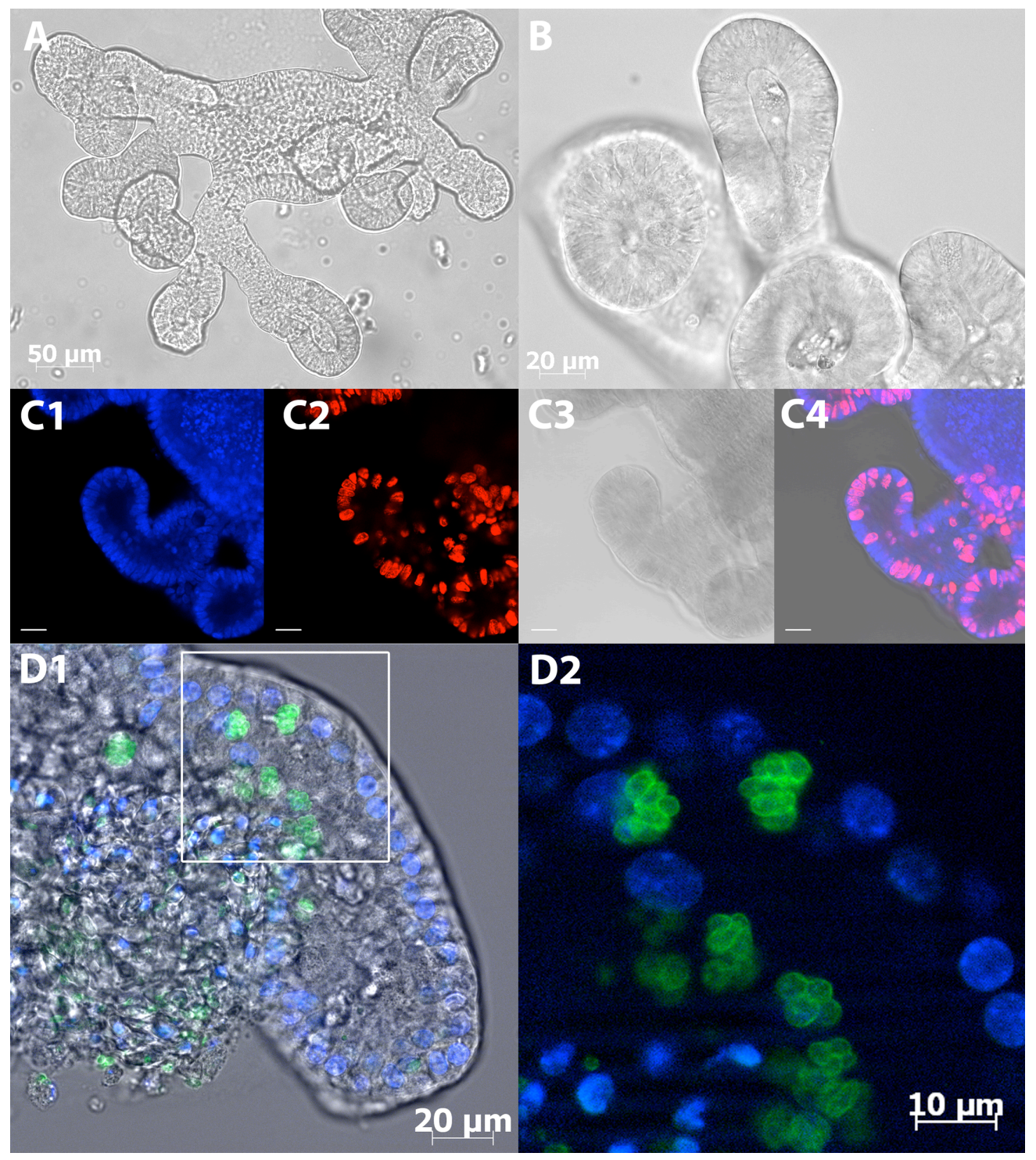




\section{References}

Ambasudhan, R., Talantova, M., Coleman, R., Yuan, X., Zhu, S., Lipton, S.A., Ding, S., 2011. Direct reprogramming of adult human fibroblasts to functional neurons under defined conditions. Cell Stem Cell 9, 113118.

Amimoto, N., Mizumoto, H., Nakazawa, K., Ijima, H., Funatsu, K., Kajiwara, T., 2011. Hepatic differentiation of mouse embryonic stem cells and induced pluripotent stem cells during organoid formation in hollow fibers. Tissue Eng. Part A 17, 2071-2078.

Ankarklev, J., Jerlstrom-Hultqvist, J., Ringqvist, E., Troell, K., Svard, S.G., 2010. Behind the smile: cell biology and disease mechanisms of Giardia species. Nat. Rev. Microbiol. 8, 413-422.

Arnold, L., Tyagi, R.K., Meija, P., Swetman, C., Gleeson, J., Perignon, J.L., Druilhe, P., 2011. Further improvements of the $P$. falciparum humanized mouse model. PLoS ONE 6, e18045.

Arrowood, M.J., 2002. In vitro cultivation of Cryptosporidium species. Clin. Microbiol. Rev. 15, 390-400.

Barragan, A., Hitziger, N., 2008. Transepithelial migration by Toxoplasma. Subcell. Biochem. 47, 198-207.

Barragan, A., Sibley, L.D., 2002. Transepithelial migration of Toxoplasma gondii is linked to parasite motility and virulence. J. Exp. Med. 195, 1625-1633.

Bauduer, F., 2012. Red cell polymorphisms and malaria: an evolutionary approach. Bull. Mem. Soc. Anthropol. Paris DOI: 10.1007/s13219-012-0060-8, 1-10.

Bei, A.K., Brugnara, C., Duraisingh, M.T., 2010. In vitro genetic analysis of an erythrocyte determinant of malaria infection. J. Infect. Dis. 202, 1722-1727.

Benere, E., Geurden, T., Robertson, L., Van Assche, T., Cos, P., Maes, L., 2010. Infectivity of Giardia duodenalis Assemblages $\mathrm{A}$ and $\mathrm{E}$ for the gerbil and axenisation of duodenal trophozoites. Parasitol. Int. 59, 634-637.

Bingham, A.K., Meyer, E.A., 1979. Giardia excystation can be induced in vitro in acidic solutions. Nature 277, 301-302.

Brehm, M.A., Racki, W.J., Leif, J., Burzenski, L., Hosur, V., Wetmore, A., Gott, B., Herlihy, M., Ignotz, R., Dunn, R., Shultz, L.D., Greiner, D.L., 2012. Engraftment of human HSCs in nonirradiated newborn NOD-scid IL2rgamma null mice is enhanced by transgenic expression of membranebound human SCF. Blood 119, 2778-2788.

Cai, J., Zhao, Y., Liu, Y., Ye, F., Song, Z., Qin, H., Meng, S., Chen, Y., Zhou, R., Song, X., Guo, Y., Ding, M., Deng, H., 2007. Directed differentiation of human embryonic stem cells into functional hepatic cells. Hepatology 45, 1229-1239.

Chen, Y.F., Tseng, C.Y., Wang, H.W., Kuo, H.C., Yang, V.W., Lee, O.K., 2012. Rapid generation of mature hepatocyte-like cells from human induced pluripotent stem cells by an efficient three-step protocol. Hepatology 55, 1193-1203.

Chieppa, M., Rescigno, M., Huang, A.Y., Germain, R.N., 2006. Dynamic imaging of dendritic cell extension into the small bowel lumen in response to epithelial cell TLR engagement. J. Exp. Med. 203, 2841-2852.

Collin, J., Lako, M., 2011. Putting a finger on stem cell biology: zinc finger nucleasedriven targeted genetic editing in human 
pluripotent stem cells. Stem Cells 29, 10211033.

Cotton, J.A., Beatty, J.K., Buret, A.G., 2011. Host parasite interactions and pathophysiology in Giardia infections. Int. J. Parasitol. 41, 925-933.

Crosnier, C., Bustamante, L.Y., Bartholdson, S.J., Bei, A.K., Theron, M., Uchikawa, M., Mboup, S., Ndir, O., Kwiatkowski, D.P., Duraisingh, M.T., Rayner, J.C., Wright, G.J., 2011. Basigin is a receptor essential for erythrocyte invasion by Plasmodium falciparum. Nature 480, 534-537.

Davila, J.C., Cezar, G.G., Thiede, M., Strom, S., Miki, T., Trosko, J., 2004. Use and application of stem cells in toxicology. Toxicol. Sci. 79, 214-223.

Dravid, G.G., Crooks, G.M., 2011. The challenges and promises of blood engineered from human pluripotent stem cells. Adv. Drug Deliv. Rev. 63, 331-341.

Duan, Y., Catana, A., Meng, Y., Yamamoto, N., He, S., Gupta, S., Gambhir, S.S., Zern, M.A., 2007. Differentiation and enrichment of hepatocyte-like cells from human embryonic stem cells in vitro and in vivo. Stem Cells 25, 3058-3068.

Ebert, A.D., Svendsen, C.N., 2010. Human stem cells and drug screening: opportunities and challenges. Nat. Rev. Drug Discov. 9, 367-372.

Faust, D.M., Marquay Markiewicz, J., Danckaert, A., Soubigou, G., Guillen, N., 2011. Human liver sinusoidal endothelial cells respond to interaction with Entamoeba histolytica by changes in morphology, integrin signalling and cell death. Cell. Microbiol. 13, 1091-1106.

Frevert, U., Usynin, I., Baer, K., Klotz, C., 2008. Plasmodium sporozoite passage across the sinusoidal cell layer. Subcell. Biochem. $47,182-197$.

Giarratana, M.C., Kobari, L., Lapillonne, H., Chalmers, D., Kiger, L., Cynober, T., Marden, M.C., Wajcman, H., Douay, L., 2005. Ex vivo generation of fully mature human red blood cells from hematopoietic stem cells. Nat. Biotechnol. 23, 69-74.

Gouagna, L.C., Bancone, G., Yao, F., Yameogo, B., Dabire, K.R., Costantini, C., Simpore, J., Ouedraogo, J.B., Modiano, D., 2010. Genetic variation in human HBB is associated with Plasmodium falciparum transmission. Nat. Genet. 42, 328-331.

Grskovic, M., Javaherian, A., Strulovici, B., Daley, G.Q., 2011. Induced pluripotent stem cells - opportunities for disease modelling and drug discovery. Nat. Rev. Drug Discov. 10, 915-929.

Hafalla, J.C., Silvie, O., Matuschewski, K., 2011. Cell biology and immunology of malaria. Immunol. Rev. 240, 297-316.

Hanna, J.H., Saha, K., Jaenisch, R., 2010. Pluripotency and cellular reprogramming: facts, hypotheses, unresolved issues. Cell $143,508-525$.

Hockemeyer, D., Soldner, F., Beard, C., Gao, Q., Mitalipova, M., DeKelver, R.C., Katibah, G.E., Amora, R., Boydston, E.A., Zeitler, B., Meng, X., Miller, J.C., Zhang, L., Rebar, E.J., Gregory, P.D., Urnov, F.D., Jaenisch, R., 2009. Efficient targeting of expressed and silent genes in human ESCs and iPSCs using zinc-finger nucleases. Nat. Biotechnol. 27, 851-857.

Hockemeyer, D., Wang, H., Kiani, S., Lai, C.S., Gao, Q., Cassady, J.P., Cost, G.J., Zhang, L., Santiago, Y., Miller, J.C., 2011. Genetic engineering of human pluripotent cells using TALE nucleases. Nat. Biotechnol. 29, 731-734. 
Ito, M., Hiramatsu, H., Kobayashi, K., Suzue, K., Kawahata, M., Hioki, K., Ueyama, Y., Koyanagi, Y., Sugamura, K., Tsuji, K., Heike, T., Nakahata, T., 2002. NOD/SCID/gamma(c)(null) mouse: an excellent recipient mouse model for engraftment of human cells. Blood 100, 3175-3182.

Kappe, S.H., Vaughan, A.M., Boddey, J.A., Cowman, A.F., 2010. That was then but this is now: malaria research in the time of an eradication agenda. Science 328, 862-866.

Kerb, R., Fux, R., Mörike, K., Kremsner, P.G., Gil, J.P., Gleiter, C.H., Schwab, M., 2009. Pharmacogenetics of antimalarial drugs: effect on metabolism and transport. Lancet Infect. Dis. 9, 760-774.

Klotz, C., Frevert, U., 2008. Plasmodium yoelii sporozoites modulate cytokine profile and induce apoptosis in murine Kupffer cells. Int. J. Parasitol. 38, 1639-1650.

Koch, R., 1876. Die Aetiologie der Milzbrand-Krankheit, begründet auf die Entwicklungsgeschichte des Bacillus Anthracis. Cohns Beiträge zur Biologie der Pflanzen 2, 277-308.

Legrand, N., Ploss, A., Balling, R., Becker, P.D., Borsotti, C., Brezillon, N., Debarry, J., de Jong, Y., Deng, H., Di Santo, J.P., Eisenbarth, S., Eynon, E., Flavell, R.A., Guzman, C.A., Huntington, N.D., Kremsdorf, D., Manns, M.P., Manz, M.G., Mention, J.-J., Ott, M., Rathinam, C., Rice, C.M., Rongvaux, A., Stevens, S., Spits, H., Strick-Marchand, H., Takizawa, H., van Lent, A.U., Wang, C., Weijer, K., Willinger, T., Ziegler, P., 2009. Humanized mice for modeling human infectious disease: challenges, progress, and outlook. Cell Host Microbe 6, 5-9.

Lie, K.H., Chung, H.C., Sidhu, K.S., 2012. Derivation, propagation, and characterization of neuroprogenitors from pluripotent stem cells (hESCs and hiPSCs). Methods Mol. Biol. 873, 237-246.

McCracken, K.W., Howell, J.C., Wells, J.M., Spence, J.R., 2011. Generating human intestinal tissue from pluripotent stem cells in vitro. Nat. Protoc. 6, 1920-1928.

Meyer, E.A., 1970. Isolation and axenic cultivation of Giardia trophozoites from the rabbit, chinchilla, and cat. Exp. Parasitol. 27, 179-183.

Miller, F.J., Bloom, F.E., 1998. Publishing controversial research. Science 282, 1045.

Mizumoto, H., Aoki, K., Nakazawa, K., Ijima, H., Funatsu, K., Kajiwara, T., 2008. Hepatic differentiation of embryonic stem cells in HF/organoid culture. Transplant. Proc. 40, 611-613.

Mueller, A.K., Labaied, M., Kappe, S.H., Matuschewski, K., 2005. Genetically modified Plasmodium parasites as a protective experimental malaria vaccine. Nature 433, 164-167.

Mussolino, C., Cathomen, T., 2012. TALE nucleases: tailored genome engineering made easy. Curr. Opin. Biotechnol. DOI:10.1016/j.copbio.2012.01.013.

Nussenzweig, R.S., Vanderberg, J., Most, H., Orton, C., 1967. Protective immunity produced by the injection of $\mathrm{x}$-irradiated sporozoites of Plasmodium berghei. Nature 216, 160-162.

Ootani, A., Li, X., Sangiorgi, E., Ho, Q.T., Ueno, H., Toda, S., Sugihara, H., Fujimoto, K., Weissman, I.L., Capecchi, M.R., Kuo, C.J., 2009. Sustained in vitro intestinal epithelial culture within a Wnt-dependent stem cell niche. Nat. Med. 15, 701-706.

Ortega, Y.R., Sanchez, R., 2010. Update on Cyclospora cayetanensis, a food-borne and 
waterborne parasite. Clin. Microbiol. Rev. $23,218-234$.

Paganotti, G.M., Gallo, B.C., Verra, F., Sirima, B.S., Nebié, I., Diarra, A., Coluzzi, M., Modiano, D., 2011. Human genetic variation is associated with Plasmodium falciparum drug resistance. J. Infect. Dis. 204, 1772-1778.

Pang, Z.P., Yang, N., Vierbuchen, T., Ostermeier, A., Fuentes, D.R., Yang, T.Q., Citri, A., Sebastiano, V., Marro, S., Südhof, T.C., Wernig, M., 2011. Induction of human neuronal cells by defined transcription factors. Nature 476, 220-223.

Pfefferkorn, E.R., 1990. The cell biology of Toxoplasma gondii, in: Wyler, D.J. (Ed.), Modern parasite biology: cellular immunological and molecular aspects. Freeman, New York, pp. 26-50.

Pfisterer, U., Kirkeby, A., Torper, O., Wood, J., Nelander, J., Dufour, A., Björklund, A., Lindvall, O., Jakobsson, J., Parmar, M., 2011. Direct conversion of human fibroblasts to dopaminergic neurons. Proc. Natl. Acad. Sci. USA 108, 10343-10348.

Prandovszky, E., Gaskell, E., Martin, H., Dubey, J.P., Webster, J.P., McConkey, G.A., 2011. The neurotropic parasite Toxoplasma gondii increases dopamine metabolism. PLoS ONE 6, e23866.

Protzer, U., Maini, M.K., Knolle, P.A., 2012. Living in the liver: hepatic infections. Nat. Rev. Immunol. 12, 201-213.

Rajarajan, K., Engels, M.C., Wu, S.M., 2012. Reprogramming of mouse, rat, pig, and human fibroblasts into iPS cells. Curr. Protoc. Mol. Biol. (Chapter 23, Unit 23.15.)

Rao, M., Ahrlund-Richter, L., Kaufman, D.S., 2012. Cord blood banking, transplantation and induced pluripotent stem cell: success and opportunities. Stem Cells $30,55-60$.

Robinton, D.A., Daley, G.Q., 2012. The promise of induced pluripotent stem cells in research and therapy. Nature 481, 295-305.

Sadelain, M., Papapetrou, E.P., Bushman, F.D., 2011. Safe harbours for the integration of new DNA in the human genome. Nat. Rev. Cancer 12, 51-58.

Sanjana, N.E., Cong, L., Zhou, Y., Cunniff, M.M., Feng, G., Zhang, F., 2012. A transcription activator-like effector toolbox for genome engineering. Nat. Protoc. 7, 171192.

Sato, T., Stange, D.E., Ferrante, M., Vries, R.G., Van Es, J.H., Van den Brink, S., Van Houdt, W.J., Pronk, A., Van Gorp, J., Siersema, P.D., Clevers, H., 2011a. Longterm expansion of epithelial organoids from human colon, adenoma, adenocarcinoma, and Barrett's epithelium. Gastroenterology 141, 1762-1772.

Sato, T., van Es, J.H., Snippert, H.J., Stange, D.E., Vries, R.G., van den Born, M., Barker, N., Shroyer, N.F., van de Wetering, M., Clevers, H., 2011b. Paneth cells constitute the niche for Lgr5 stem cells in intestinal crypts. Nature 469, 415-418.

Sato, T., Vries, R.G., Snippert, H.J., van de Wetering, M., Barker, N., Stange, D.E., van Es, J.H., Abo, A., Kujala, P., Peters, P.J., Clevers, H., 2009. Single Lgr5 stem cells build crypt-villus structures in vitro without a mesenchymal niche. Nature 459, 262-265.

Schuster, F.L., 2002. Cultivation of Plasmodium spp. Clin. Microbiol. Rev. 15, 355-364.

Schwartz, R.E., Linehan, J.L., Painschab, M.S., Hu, W.S., Verfaillie, C.M., Kaufman, D.S., 2005. Defined conditions for development of functional hepatic cells from 
human embryonic stem cells. Stem Cells Dev. 14, 643-655.

Sekiya, S., Suzuki, A., 2011. Direct conversion of mouse fibroblasts to hepatocyte-like cells by defined factors. Nature 475, 390-393.

Silvie, O., Mota, M.M., Matuschewski, K., Prudencio, M., 2008. Interactions of the malaria parasite and its mammalian host. Curr. Opin. Microbiol. 11, 352-359.

Smith, P.D., Gillin, F.D., Spira, W.M., Nash, T.E., 1982. Chronic giardiasis: studies on drug sensitivity, toxin production, and host immune response. Gastroenterology 83, 797803.

Song, Z., Cai, J., Liu, Y., Zhao, D., Yong, J., Duo, S., Song, X., Guo, Y., Zhao, Y., Qin, H., Yin, X., Wu, C., Che, J., Lu, S., Ding, M., Deng, H., 2009. Efficient generation of hepatocyte-like cells from human induced pluripotent stem cells. Cell Res. 19, 12331242.

Spence, J.R., Mayhew, C.N., Rankin, S.A., Kuhar, M.F., Vallance, J.E., Tolle, K., Hoskins, E.E., Kalinichenko, V.V., Wells, S.I., Zorn, A.M., Shroyer, N.F., Wells, J.M., 2011. Directed differentiation of human pluripotent stem cells into intestinal tissue in vitro. Nature 470, 105-109.

Stark, D., Barratt, J.L., van Hal, S., Marriott, D., Harkness, J., Ellis, J.T., 2009. Clinical significance of enteric protozoa in the immunosuppressed human population. Clin. Microbiol. Rev. 22, 634-650.

Strowig, T., Flavell, R.A., 2012. Humanized mouse models of infectious diseases. Drug Discov. Today Dis. Models 9, e11-e16.

Takahashi, K., Yamanaka, S., 2006. Induction of pluripotent stem cells from mouse embryonic and adult fibroblast cultures by defined factors. Cell 126, 663676.

Taylor, A.E.R., Baker, J.R., 1987. In vitro methods for parasite cultivation. Academic Press, London.

Terry, C., Hughes, R.D., 2009. An optimised method for cryopreservation of human hepatocytes. Methods Mol. Biol. 481, 25-34.

Thomson, J.A., Itskovitz-Eldor, J., Shapiro, S.S., Waknitz, M.A., Swiergiel, J.J., Marshall, V.S., Jones, J.M., 1998. Embryonic stem cell lines derived from human blastocysts. Science 282, 1145-1147.

Timmins, N.E., Nielsen, L.K., 2011. Manufactured RBC--rivers of blood, or an oasis in the desert? Biotechnol. Adv. 29, 661-666.

Touboul, T., Hannan, N.R., Corbineau, S., Martinez, A., Martinet, C., Branchereau, S., Mainot, S., Strick-Marchand, H., Pedersen, R., Di Santo, J., Weber, A., Vallier, L., 2010. Generation of functional hepatocytes from human embryonic stem cells under chemically defined conditions that recapitulate liver development. Hepatology 51, 1754-1765.

Traggiai, E., Chicha, L., Mazzucchelli, L., Bronz, L., Piffaretti, J.C., Lanzavecchia, A., Manz, M.G., 2004. Development of a human adaptive immune system in cord blood celltransplanted mice. Science 304, 104-107.

Vierbuchen, T., Wernig, M., 2011. Direct lineage conversions: unnatural but useful? Nat. Biotechnol. 29, 892-907.

Visvesvara, G.S., Garcia, L.S., 2002. Culture of protozoan parasites Clin. Microbiol. Rev. $15,327-328$.

Wendte, J.M., Gibson, A.K., Grigg, M.E., 2011. Population genetics of Toxoplasma gondii: New perspectives from parasite 
genotypes in wildlife. Vet. Parasitol. 182, 96-111.

Yui, S., Nakamura, T., Sato, T., Nemoto, Y., Mizutani, T., Zheng, X., Ichinose, S.,
Nagaishi, T., Okamoto, R., Tsuchiya, K., Clevers, H., Watanabe, M., 2012. Functional engraftment of colon epithelium expanded in vitro from a single adult $\operatorname{Lgr} 5(+)$ stem cell. Nat. Med. 18, 618-623. 


\section{Supplementary Table 1: Selection of intenet addresses of iPSC and related resources}

Mouse stem cell resources

RIKEN

Mutant Mouse Regional Resource Centers (MMRRC) Baygenomics

EMMA - The European Mouse Mutant

Archive

Mount Sinai School of Medicine Soriano $\mathrm{Lab}$

Sanger Gene Trap Consortium

International Genetrap Consortium

Center for iPS Cell Research and Application
URL

http://www2.brc.riken.jp/lab/cell/s5 list.cgi?key=e

http://www.mmrrc.org/catalog/overview BG.php

http://www.emmanet.org/

http://research.mssm.edu/soriano/lab/gene trap.html

http://www.sanger.ac.uk/resources/mouse/sigtr/

http://www.genetrap.org/

http://www.cira.kyoto-u.ac.jp/e/research/material_1.html

\section{Depositories of Human stem cells \& primary cells}

Boston Univ. Med. School iPS Bank

Project

WiCEll Research Institute iPS Distribution

International Stem Cell Repository

The Human Genetic Cell Repository (NIGMS)

LGC Standards/ATCC

HSCI iPS Cell Core Facility

European Human Embryonic Stem Cell Registry

HPA Culture Collections

Health Science Research Resources Bank (Japan)

System Biosciences (commercial)

Sigma-Aldrich iPS Cell Design Studio (commercial) http://www.bumc.bu.edu/evanscenteribr/the-arcs/the-arcs/regenerativemedicine/

http://www.wicell.org/index.php?option $=$ com content $\&$ task $=$ category $\&$ $\underline{\mathrm{id}=348 \& \text { Itemid }=262 \& \text { sectionid }=19}$

http://www.umassmed.edu/iscr/index.aspx

http://ccr.coriell.org/Sections/Collections/NIGMS/

http://www.lgcstandardsatcc.org/LGCAdvancedCatalogueSearch/ProductDescription/tabid/1068 Default.aspx\#aPrope3e6d

http://www.hsci.harvard.edu/ipscore/node/3

http://www.hescreg.eu/

http://www.hpacultures.org.uk/products/celllines/primarycells/index.jsp

http://www.jhsf.or.jp/bank/Category-Index.html

http://www.systembio.com/stem-cell-research/ips-cell-lines http://www.sigmaaldrich.com/life-science/stem-cell-biology/ips-celldesign-studio.html

\section{Plasmids for iPSC generation and modification at Addgene}

Plasmids for Stem Cell Research

http://www.addgene.org/stemcell/

Zinc Finger Consortium Reagents

http://www.addgene.org/zfc/

TALEN Kits

http://www.addgene.org/TALEN/ 